\title{
Purification of Olive Mill Wastewater Using Microfiltration Membrane Technology
}

\author{
Konstantinos B. Petrotos ${ }^{1, *}$, Themistocles Lellis ${ }^{1}$, Maria I. Kokkora ${ }^{2}$ and \\ Paschalis E. Gkoutsidis ${ }^{1}$ \\ ${ }^{1}$ Technological Educational Institute (TEI) of Thessaly, School of Agricultural Technology, Department of \\ Biosystems Engineering, Perifereiaki Larissis - Trikalon, 41110, Larissa, Greece \\ ${ }^{2}$ Technological Research Center of Thessalia, TEl of Thessaly, 41110, Larissa, Greece
}

\begin{abstract}
Olive mill wastewater (OMWW), a by-product of the olive oil extraction process, is a severe polluting waste, but also a source of antioxidants; polyphenols, especially hydroxytyrosol. This study aimed at investigating the potential of microfiltration (MF) for separating the polyphenols from OMWW. OMWW treatment consisted of a preliminary centrifugation step, followed by MF for the separation of fats and polyphenols. Two types of ceramic MF membranes were used. MF flux ranged between 78 and $95 \mathrm{~kg} \mathrm{~m}^{-2} \mathrm{~h}^{-1}$, indicating the applicability of the described process on commercial scale. Better results were obtained with MF membrane of $50 \mathrm{~nm}$ pore size, due to its higher porosity compared to the membrane of $200 \mathrm{~nm}$ pore size. The optimum operative conditions were transmembrane pressure of $3.5 \mathrm{bar}$, flow rate of $10 \mathrm{~m} \mathrm{~s}^{-1}$, and temperature of approximately $55^{\circ} \mathrm{C}$. A 3-month storage of OMWW prior to treatment resulted in a $20 \%$ decrease in permeate flux, indicating that direct processing of the OMWW is necessary. Membrane pollution was not a problem for MF operation and did not affect membrane permeability significantly. Restoring the permeability of water to baseline levels after each use, confirmed the successful cleaning regime applied. The microfiltrate was an excellent antioxidant, which contained useful polyphenols, including hydroxytyrosol, tyrosol, $p$ coumaric acid, caffeic acid and catechin.
\end{abstract}

Keywords: Permeate flux, polyphenols, membrane cleaning, OMWW storage, microfiltration.

\section{INTRODUCTION}

Olive oil production is a key economic activity in the Mediterranean region. Olive mill wastewater (OMWW), a by-product of the olive oil extraction process, is a mixture of vegetation water containing soft tissues of the olive fruit, and the water used in the various stages of the oil extraction process, and is considered to be a significant polluting waste in all Mediterranean countries. OMWW constitutes a serious environmental problem in the area, mainly due to its low $\mathrm{pH}$, high solids and organic compounds, high COD content, phytotoxic properties and resistance to biodegradation caused by its phenolic compounds [1, 2]. In terms of pollution effect, $1 \mathrm{~m}^{3}$ of OMWW is assumed to be equivalent to $100-200 \mathrm{~m}^{3}$ of domestic sewage.

On the other hand, however, phenolic compounds from olive fruit and its by-products include a wide range of biological activities, such as antioxidant, antiinflammatory, antibacterial, and antiviral functions [2, 3]. Natural antioxidants are widely used in the pharmaceutical, cosmetic and food industry nowadays, as currently used synthetic antioxidants have been suspected to cause or promote undesirable effects on

${ }^{*}$ Address correspondence to this author at the Technological Educational Institute (TEI) of Thessaly, School of Agricultural Technology, Department of Biosystems Engineering, Perifereiaki Larissis - Trikalon, 41110, Larissa, Greece; Tel: +302410684524; Fax: +302410613153; E-mail: petrotos@teilar.gr human health, and also to contribute towards oxidative degradation of food [4-6]. Olive mill wastewater is an excellent source of natural antioxidants. Thus, OMWW treatment that will allow for phenols collection may lead to economic benefits [7].

One of the most promising methods for the treatment of OMWW, considering effectiveness, environmental impact and cost, is membrane filtration [2]. Membrane technology reduces the OMWW organic load and suspended solids content [1, 3, 8]. Microfiltration (MF) and ultrafitration (UF) may be used as a primary treatment step, while nanofiltration (NF) and reverse osmosis (RO) for the final treatment of OMWW [3], or alternatively a pretreatment step could be employed, such as separation with centrifugation, filter-press, vacuum pressure filtering, screening [9-11] and afterwards final treatment using MF or UF. It is reported that OMWW using MF technology, without a pre-treatment step, is possible to reduce oil and grease content by about $94 \%$ [1].

Membrane fouling, however, is a common problem related to OMWW purification that severely reduces the permeate flux, resulting in changes in both membrane selectivity and permeability. In general, there are two important parameters for consideration regarding the treatment of olive mill wastewater with membrane technology: a) the extent of separation of the 
polyphenols from the mass of waste, and b) the filtration flux of the membranes used. The degree of separation is important because in the case that polyphenols are efficiently separated from the mass of liquid waste, then olive mill wastewater can be handled as common wastewater and be fed into biological treatment, or used for crop irrigation. Furthermore, the polyphenols separated may be utilized in the pharmaceutical and cosmetic industry.

In this study, two commercial MF membranes with different properties are used to separate the polyphenols from oil substances. The effects of temperature, flow rate, transmembrane pressure, membrane pore size and OMWW storage time on the membrane performance during OMWW treatment process are investigated. Also, the efficiency of the membrane cleaning was studied.

\section{MATERIALS AND METHODS}

\subsection{Olive Mill Wastewater}

The olive mill wastewater used in this study was collected from "Tsakiridis" olive mill, in Pournari, Larissa, central Greece. The olive oil extraction process employed was the typical three-phase decanter centrifugation. The raw OMWW produced was centrifuged at $1200 \mathrm{rpm}$ using a rotary finisher bearing a stainless screen with holes of $150 \mu \mathrm{m}$ diameter.

\subsection{Microfiltration (MF)}

The pretreated OMWW was microfiltered to separate the polyphenols (permeate) from oil substances. The permeate could then be further treated with polyphenol absorbing resins to extract the polyphenols. A microfiltration rig was constructed to carry out the experiments (Figure 1). The rig consisted of the following elements: i) two 304 stainless steel MF modules, type CMV3-30 (Jiangsu Sainty Machinery I/E Co., Ltd). Each module was constructed to accommodate three MF membranes of the same pore size, resulting in a total surface area of $0.69 \mathrm{~m}^{2}$, ii) a pump, with volumetric capacity of $50 \mathrm{~m}^{3} \mathrm{~h}^{-1}$ and pressure range between 0 and 6 bar, iii) a $1 \mathrm{~m}^{3}$ feed tank, equipped with a temperature control system, iv) a pressure control system, installed at the entrance of membrane module, and v) plastic flexible pipes, used to interconnect the rig elements.

The two types of MF membrane used were ceramic and commercially available (Jiangsu Sainty Machinery I/E Co., Ltd). The first MF membrane was of $200 \mathrm{~nm}$ pore size (CMF 19033-200nm), whereas the second of $50 \mathrm{~nm}$ pore size (CMF 19033-50nm). Both MF membranes had a total length of $1178 \mathrm{~mm}$, surface area of $0.23 \mathrm{~m}^{2}$, and consisted of 19 channels, with channel internal diameter of $25 \mathrm{~mm}$.

The MF process started with membrane cleaning, as described in section 2.3. Following the cleaning

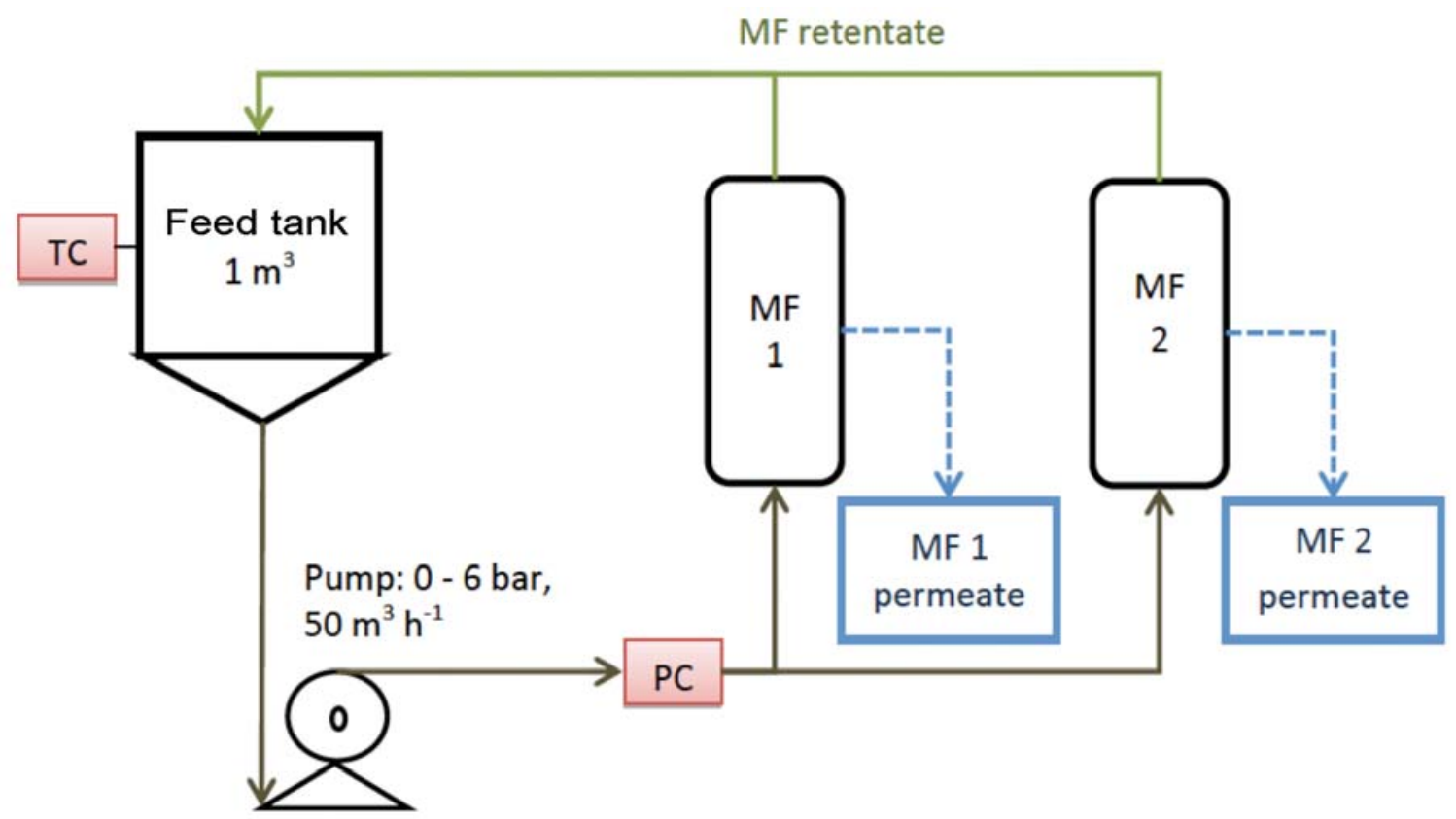

Figure 1: Experimental rig (PC: pressure control, TC: temperature control, MF1: microfiltration module 1, containing three MF membranes of $50 \mathrm{~nm}$ pore size, MF 2: microfiltration module 2, containing three MF membranes of $200 \mathrm{~nm}$ pore size). 
procedure, MF of distilled water took place, aiming at recording a reference flux to be used as "control" for comparison with the flux obtained for OMWW MF at the same experimental conditions, and also to evaluate the effectiveness of the cleaning regime. Following this step, the filtration of OMWW samples commenced. The feed tank was filled up with a quantity of about $1 \mathrm{~m}^{3}$ of pretreated OMWW. Initially, the temperature was set at $45{ }^{\circ} \mathrm{C}$, OMWW flow rate was $10 \mathrm{~m} \mathrm{~s}^{-1}$ and the membrane flux was measured at transmembrane pressure ranging between 1 and 4.5 bar. Then, at the same temperature $\left(45{ }^{\circ} \mathrm{C}\right)$ and at transmembrane pressure of 2.5 bar, the effect of the following flow rates: 5,10 and $15 \mathrm{~m} \mathrm{~s}^{-1}$ on permeate flux was studied. Finally, the effect of temperature, within the range of 20 $-80{ }^{\circ} \mathrm{C}$, was investigated at transmembrane pressure of 2.5 bar and flow rate of $10 \mathrm{~m} \mathrm{~s}^{-1}$.

The performance of the MF membrane was further determined by studying the changes in membrane permeate flux as a function of time, which is also an indication of membrane fouling propensity. MF flux was recorded at $15 \mathrm{~s}$ interval by weighing the mass of the permeate produced. MF flux was calculated in $\mathrm{kg} \mathrm{m}^{-2} \mathrm{~h}^{-1}$, using the following equation

Flux $=W /(A x B)$

where $\mathrm{W}$ is the weight of the permeate $(\mathrm{kg})$ collected within time $B=1 / 240 \mathrm{~h}$ from a surface area of $A=0.69$ $\mathrm{m}^{2}$.

Measurements were performed at least an hour following the beginning of the experimental rig operation in order to avoid the sharp decrease in the permeability observed due to the initial membrane pollution.

The permeate was collected into a plastic tank, whereas the retentate was returned into the feed tank, where it was mixed with the remaining OMWW sample and then was circulated again for further concentration. The MF process lasted for 20 hours.

The determination of polyphenols in the MF permeate was carried out using high performance liquid chromatography (HPLC) analysis. The equipment utilized was a HITACHI coupled to an autosampler L2200, pump L-2130, column oven L-2300 and diode array detector L-2455 and controlled by Agilent EZChrom Elite software. The column was a Pinnacle II RP C18, $3 \mu \mathrm{m}, 150 \times 4.6 \mathrm{~mm}$ (Restek), protected by a Kromasil 100-5 C18 guard cartridge starter kit for $3.0 / 4.6 \mathrm{~mm}$ id. Column oven was set at $40{ }^{\circ} \mathrm{C}$. Eluent $(\mathrm{A})$ and $(\mathrm{B})$ were $0.02 \mathrm{M}$ sodium acetate adjusted at
$\mathrm{pH}=3.2$ with acetic acid and pure acetonitrile, respectively. The flow rate was $1 \mathrm{~mL} \min ^{-1}$ and the injection volume was $20 \mu \mathrm{L}$. The elution gradient profile was as follows: started (A) 100\%; $3 \mathrm{~min}, 88 \%$; $10 \mathrm{~min}$, $79 \%$; $12 \mathrm{~min}, 61 \%$; $18 \mathrm{~min}, 46 \%$; $25 \mathrm{~min}, 40 \%$; $28 \mathrm{~min}$, $100 \%$. The elute was monitored at $280 \mathrm{~nm}$ for oleuropein, hydroxytyrosol and tyrosol and at $355 \mathrm{~nm}$ for flavonols. Total polyphenols was determined according to FolinCiocalteu method.

\subsection{Membrane Cleaning}

Once the MF process was completed, the membranes were cleaned in order to prevent the reduction of membrane permeability due to particle depositions onto membrane surface, and also to investigate the potential of restoring the membrane permeability to its original condition. The membrane cleaning procedure involved liquid circulation under zero transmembrane pressure and lasted approximately $4 \mathrm{~h}$. Both alkaline cleaning (detergents used were: P3-ultrasil 110, P3-ultrasil 69, P3-ultrasil 67 and P3-ultrasil 02) and acidic cleaning (P3-ultrasil 75) was applied. Similar procedure was applied successfully to MF membrane cleaning following slaughterhouse blood circulation [12].

In detail, the cleaning procedure involved the following steps: 1) membrane rinsing with deionized water under maximum flow rate for complete removal of the residual waste, lasting at least $20 \mathrm{~min}, 2$ ) circulation of a $150 \mathrm{~L}$ aqueous solution containing 1080 g P3-ultrasil 69, $480 \mathrm{~g}$ P3-ultrasil 67 and $120 \mathrm{~g} \mathrm{P3-}$ ultrasil 02 (solution temperature was $48^{\circ} \mathrm{C}$ ) for $45 \mathrm{~min}$, at zero transmembrane pressure and maximum flow rate, 3) membrane rinsing with deionized water for 15 min, 4) circulation of a $90 \mathrm{~L}$ aqueous solution containing $360 \mathrm{~g}$ P3-ultrasil 75 (solution temperature was $48{ }^{\circ} \mathrm{C}$ ) for $30 \mathrm{~min}$, at zero transmembrane pressure and maximum flow rate, 5) membrane rinsing with deionized water for $15 \mathrm{~min}, 6$ ) circulation of a $90 \mathrm{~L}$ aqueous solution containing $720 \mathrm{~g}$ P3-ultrasil 110 (solution temperature was $48{ }^{\circ} \mathrm{C}$ ) for $20 \mathrm{~min}$, at zero transmembrane pressure and maximum flow rate, 7 ) membrane rinsing with deionized water for $15 \mathrm{~min}$, and 8) final rinsing and membrane preservation using $0.1 \%$ potassium metabisoulfite solution.

\section{RESULTS AND DISCUSSION}

\subsection{The Effect of Flow Rate on MF Flux}

As shown in Figure 2, the maximum MF flux was observed at OMWW flow rate of $10 \mathrm{~m} \mathrm{~s}^{-1}$. Higher flow 
rate than $10 \mathrm{~m} \mathrm{~s}^{-1}$ resulted in lower flux. The same result was observed with lower flow rate than $10 \mathrm{~m} \mathrm{~s}^{-1}$. The decrease in flux after reaching the maximum value of approximately $95 \mathrm{~kg} \mathrm{~m}^{-2} \mathrm{~h}^{-1}$, was most likely due to the fact that when OMWW flow rate was higher than 10 $\mathrm{m} \mathrm{s}^{-1}$, the oil molecules in the OMWW (oil content was about $1-2 \%$ ) tended to form emulsion, causing the flux to decrease.

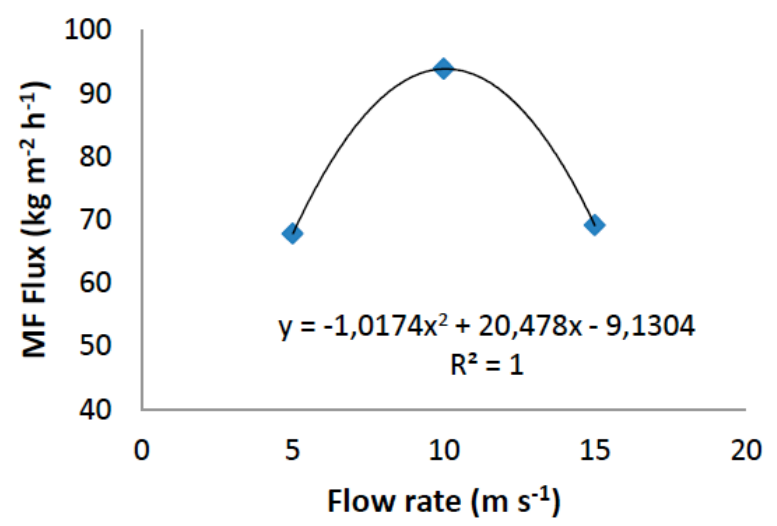

Figure 2: The effect of OMWW flow rate on microfiltration flux (temperature: $45^{\circ} \mathrm{C}$, transmembrane pressure: 2.5 bar, membrane pore size: $200 \mathrm{~nm}$ ).

\subsection{The Effect of Transmembrane pressure on MF flux}

OMWW MF flux tripled with increasing transmembrane pressure from 1 to 3.5 bar (see Figure 3). Further increase in transmembrane pressure to 4.5 bars did not significantly affect the flux. This was mainly attributed to the boundary level which was formed at these pressures due to the existence of macromolecules and fiber in combination with limited oil substances passed through the membranes. Hence, the optimum transmembrane pressure was found to be 3.5 bar.

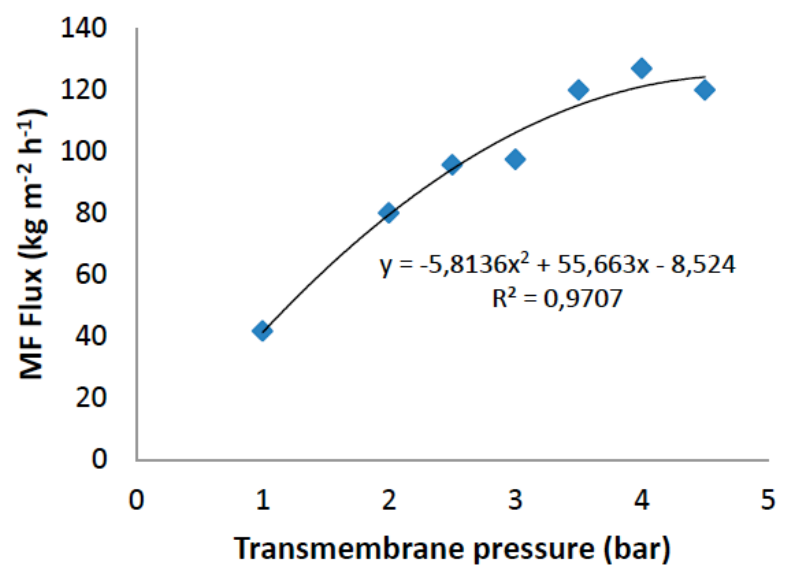

Figure 3: The effect of transmembrane pressure on microfiltration flux (temperature: $45^{\circ} \mathrm{C}$, flow rate: $10 \mathrm{~m} \mathrm{~s}^{-1}$, membrane pore size: $200 \mathrm{~nm}$ ).

\subsection{The Effect of Temperature on MF Flux}

The MF flux increased linearly with the increase in temperature, from 30 to $55{ }^{\circ} \mathrm{C}$, as shown in Figure 4 . As a matter of fact, the value of membrane flux at the temperature of $55^{\circ} \mathrm{C}$ was double compared to the flux at the temperature of $30{ }^{\circ} \mathrm{C}$. However, when temperature increased to levels higher than $60^{\circ} \mathrm{C}$, an undesirable polymerization of the material was observed, which resulted in pore blockage. In addition, the presence of polymerized materials could interrupt the flowing pattern of the entire filtration system and because of this, a hot water tank with a spare pump should be placed next to the MF unit for immediate membrane rinsing in the case of flow interruption in order to prevent irreversible membrane damage.

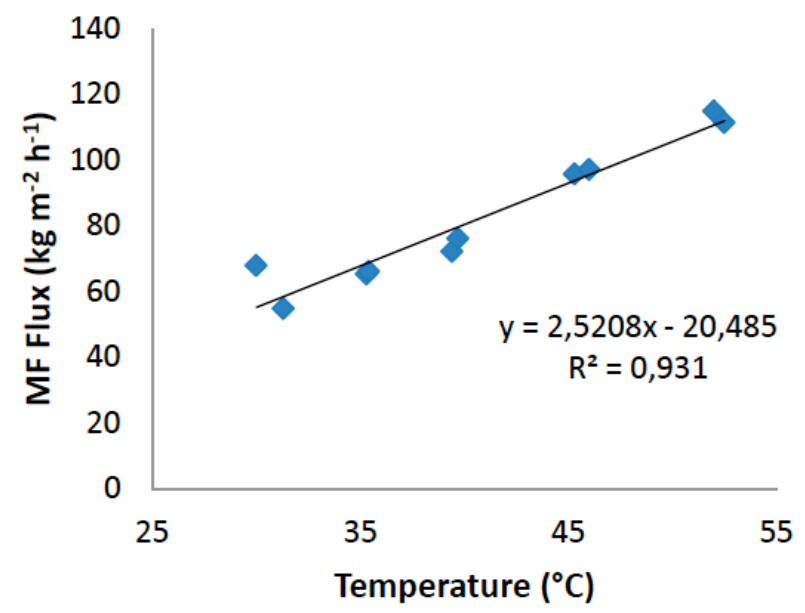

Figure 4: The effect of temperature on microfiltration flux (transmembrane pressure: 2.5 bar, flow rate: $10 \mathrm{~m} \mathrm{~s}^{-1}$, membrane pore size: $200 \mathrm{~nm}$ ).

\subsection{Membrane Pore Size}

During the 20-hour period of continuous operation, the average flux through the MF membrane with the pore size of $50 \mathrm{~nm}$ was $95.33 \mathrm{~kg} \mathrm{~m}^{-2} \mathrm{~h}^{-1}$, whereas through the MF membrane with the pore size of 200 $\mathrm{nm}$ was $78.70 \mathrm{~kg} \mathrm{~m}^{-2} \mathrm{~h}^{-1}$. The lower the membrane pore size the higher the flux. This was attributed to the fact that the membrane with the smaller pore size has higher porosity. Similar trends were observed when the membranes were tested with deionized water. It is reported that the average water flux through the MF membrane with the pore size of $50 \mathrm{~nm}$ was $626.07 \mathrm{~kg}$ $\mathrm{m}^{-2} \mathrm{~h}^{-1}$ (under transmembrane pressure of 1 bar and temperature of $25^{\circ} \mathrm{C}$ ), compared to $344.35 \mathrm{~kg} \mathrm{~m}^{-2} \mathrm{~h}^{-1}$ reported in the MF of $200 \mathrm{~nm}$.

With respect to the variation of flux with time during the 20-hour period of continuous operation, the results 
for the two membrane types are presented in Figure 5. There was a mild variation in the flux of the $200 \mathrm{~nm}$ pore size membrane, with a slight tendency for decreasing the flux after 15 hours of continuous operation. On the other hand, the flux of the $50 \mathrm{~nm}$ pore size membrane showed significant variation through the 20 hour operation period. MF flux increased with time, picked within the third 4-hour period, and then started to decrease. At the end of the 20-hour period, MF flux of the $50 \mathrm{~nm}$ pore size membrane was about $22 \%$ lower than the initial flux. It is important to note that for both cases, the final value of flux is close to $70 \mathrm{~kg} \mathrm{~m}^{-2} \mathrm{~h}^{-1}$, which is significantly higher than that of $15 \mathrm{~kg} \mathrm{~m}^{-2} \mathrm{~h}^{-1}$, which is the limit established by the technical and international practice for a membrane process to be considered acceptable, from an economic point of view, for industrial application [13]. It is evident therefore, that there was no problem with membrane fouling during the 20-hour period of continuous operation. The high flow rate (10 $\mathrm{m} \mathrm{s}^{-1}$ ) used acted as a dynamic method of cleaning the membrane surface, thus preventing membrane fouling.

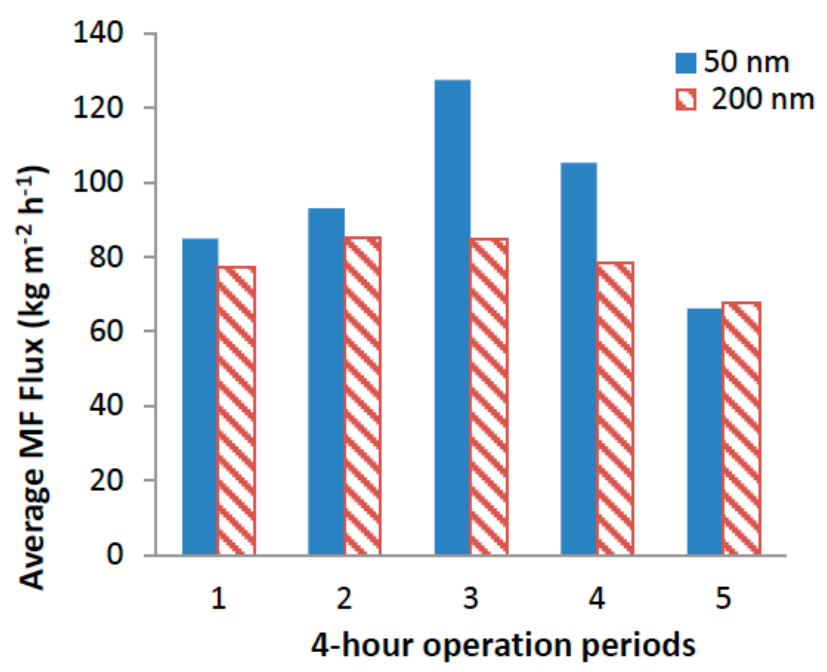

Figure 5: The effect of membrane pore size on OMWW microfiltration flux (transmembrane pressure: 2.6 bar, flow rate: $10 \mathrm{~m} \mathrm{~s}^{-1}$, temperature: $48^{\circ} \mathrm{C}$ ).

\subsection{Membrane Cleaning}

After a continuous 20-hour operation with OMWW, the membranes were cleaned according to the procedure described in section 2.3. Once the cleaning process was completed, the MF flux of deionized water was recorded in order to estimate the effectiveness of the cleaning regime applied. As presented in Figure 6 , water MF flux was varied between 340 and $400 \mathrm{~kg} \mathrm{~m}^{-2}$ $\mathrm{h}^{-1}$, which indicates that the flux remained practically steady. Hence, the membrane cleaning method used was able to restore membrane permeability after its operation with OMWW. Therefore, the suggested cleaning regime could be applied to support the operation of an industrial OMWW purifying unit by MF.

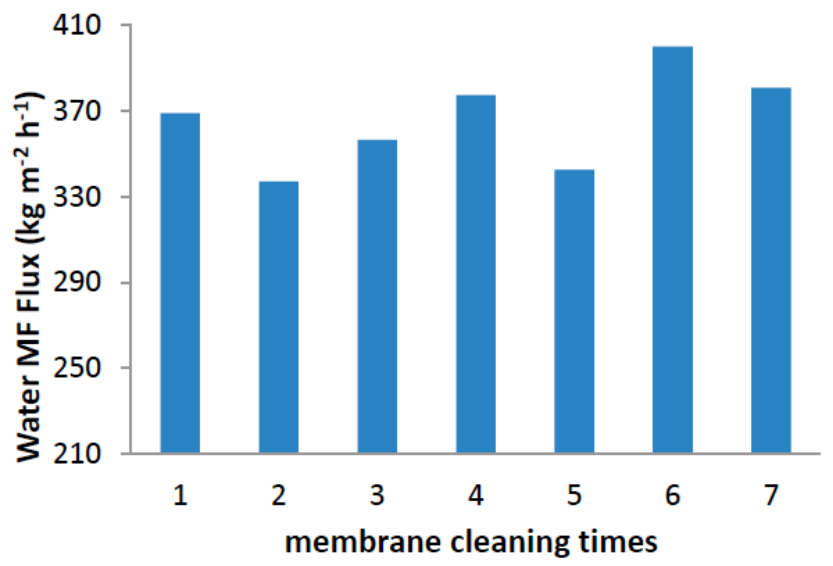

Figure 6: Deionized water microfiltration flux following membrane cleaning (transmembrane pressure: 1 bar, flow rate: $10 \mathrm{~m} \mathrm{~s}^{-1}$, temperature: $25^{\circ} \mathrm{C}$, membrane pore size: 200 $\mathrm{nm})$.

\subsection{Microfiltrate Yield and Quality}

Microfiltrate (permeate) yield was found to depend on the storage time of OMWW. In the case of fresh OMWW, the amount of MF permeate produced (microfiltrate yield) was $80 \%$ the amount of OMWW processed. In the case that OMWW was processed by MF after a three-month period following its production, microfiltrate yield was $60 \%$ the amount of OMWW processed. This was attributed to the lower viscosity of the fresh OMWW compared to the stored one.

The permeate produced was an aqueous solution of low viscosity, dark colour, and the characteristic odour of olive oil. The permeate, with regard to its antioxidant potential, was of good quality, as it contained olive polyphenols, especially hyrdo-tyrosol. Total polyphenols were determined at $38500 \mathrm{ppm}$ on dry matter basis, expressed as gallic acid (Folin-Ciocalteu method). In detail, the microfiltrate consisted of 5000 ppm hydro-tyrosol, 5540 ppm tyrosol, 200 ppm caffeic acid, 420 ppm p-coumaric acid (dry matter basis), and also of smaller amounts of anthocyanin, catechin and epicatechin. Permeate total solids content was approximately $10 \% \mathrm{w} / \mathrm{w}$, and it had $24^{\circ} \mathrm{Bx}$. The $\mathrm{pH}$ was 4.5 .

\section{CONCLUSIONS}

From the measured OMWW MF fluxes it is concluded that the described process can be applied to commercial scale, as the average values of flux were 
high, in the range of $78-95 \mathrm{~kg} \mathrm{~m}^{-2} \mathrm{~h}^{-1}$. Better results were obtained with the MF membrane of $50 \mathrm{~nm}$ pore size, due to its higher porosity compared to the membrane of $200 \mathrm{~nm}$ pore size. The optimum operative conditions were transmembrane pressure of 3.5 bar, flow rate of $10 \mathrm{~m} \mathrm{~s}^{-1}$, and temperature of approximately $55^{\circ} \mathrm{C}$. Higher transmembrane pressure did not cause flux to increase significantly, whilst temperatures higher than $60{ }^{\circ} \mathrm{C}$ tended to block membrane pore, and higher flow rates would decrease the flux. MF performance decreased by about $20 \%$, with a shift from using fresh OMWW to 3-monthsstored OMWW, which suggested that direct processing of the OMWW is highly recommended. Membrane pollution was not a problem for MF operation, provided that the operative conditions were the appropriate (e.g. the temperature did not exceed $60{ }^{\circ} \mathrm{C}$ ), and did not affect membrane permeability significantly. Restoring membrane permeability to its baseline levels after each use, confirmed the successful cleaning regime applied. The analysis of the microfiltrate (permeate) showed that it was an excellent antioxidant which contained a number of useful polyphenols, such as hydroxytyrosol, tyrosol, $p$-coumaric acid, caffeic acid and catechin.

\section{ACKNOWLEDGEMENTS}

This research has been co-financed by the European Union (European Social Fund - ESF) and Greek national funds through the Operational Program "Education and Lifelong Learning" of the National Strategic Reference Framework (NSRF) - Research Funding Program: ARCHIMEDES III. Investing in knowledge society through the European Social Fund.

\section{REFERENCES}

[1] Zirehpour A, Jahanshahi M, Rahimpour A. Unique membrane process integration for olive oil mill wastewater purification. Sep Purif Technol 2012; 96: 124-7. http://dx.doi.org/10.1016/j.seppur.2012.05.028

[2] Zaglis DP, Arvaniti EC, Papadakis VG, Paraskeva CA. Sustainability analysis and benchmarking of olive mill wastewater treatment methods. J Chem Technol Biotechnol 2013; 88: 742-8.

http://dx.doi.org/10.1002/jctb.4036

[3] El-Abbassi A, Hafidi A, Khayet M, García-Payo MC Integrated direct contact membrane distillation for olive mill wastewater treatment. Desalination 2013; 323: 31-7. http://dx.doi.org/10.1016/j.desal.2012.06.014

[4] Fki I, Allouche N, Sayadi S. The use of polyphenolic extract, purified hydrotyrosol and 3,4-dihydroxyphenyl acetic acid from olive mill wastewater for the stabilization of refined oils: a potential alternative to synthetic antioxidants. Food Chem 2005; 93: 197-7. http://dx.doi.org/10.1016/j.foodchem.2004.09.014

[5] LafkaT-I, Lazou AE, Sinanoglou VJ, Lazos ES. Phenolic and antioxidant potential of olive mill wastes. Food Chem 2011; 125: $92-6$

http://dx.doi.org/10.1016/j.foodchem.2010.08.041

[6] De Marco E, Savarese M, Paduano A, Sacchi R. Characterization and fractionation of phenolic compounds extracted from olive oil mill wastewaters. Food Chem 2007; 104: 858-9.

http://dx.doi.org/10.1016/j.foodchem.2006.10.005

[7] Garcia-Castello E, Cassano A, Criscuoli A, Conidi C, Drioli E. Recovery and concentration of polyphenols from olive mill wastewaters by integrated membrane system. Water Res 2010; 44: 3883-9.

http://dx.doi.org/10.1016/j.watres.2010.05.005

[8] Russo C. A new membrane process for the selective fractionation and total recovery of polyphenols, water and organic substances from vegetation waters (VW). J Membr Sci 2007; 288: 239-7. http://dx.doi.org/10.1016/j.memsci.2006.11.020

[9] Turano E, Curcio S, De Paola MG, Calabr V, lorio G. An integrated centrifugation-ultrafiltration system in the treatment of olive mill wastewater. J Membr Sci 2002; 209: 519-12. http://dx.doi.org/10.1016/S0376-7388(02)00369-1

[10] Paraskeva CA, Papadakis VG, Tsarouchi E, Kanellopoulou DG, Koutsoukos PG. Membrane processing for olive mill wastewater fractionation. Desalination 2007; 213: 218-11. http://dx.doi.org/10.1016/i.desal.2006.04.087

[11] Gkoutsidis PE, Petrotos KB, Kokkora MI, Tziortziou AD, Christodouloulis K, Goulas P. Olive mill waste water (OMWW) treatment by diafiltration. Desalin Water Treat 2011; 30: 237-9.

http://dx.doi.org/10.5004/dwt.2011.2077

[12] Kokkora MI, Petrotos KB, Gkoutsidis PE, Mpoulmpos C. Application of membrane technology to slaughterhouse blood to produce edible powdered protein mixture. J Memb Separ Tech 2012; 1: 35-7.

[13] Petrotos KB. The study of the tomato juice concentration by direct osmosis membrane technology. PhD Thesis, Aristotle University of Thessaloniki, School of Engineering, Dept. of Chemical Engineering 1999.

\section{DOl: http://dx.doi.org/10.6000/1929-6037.2014.03.01.5}

(c) 2014 Petrotos et al.; Licensee Lifescience Global.

This is an open access article licensed under the terms of the Creative Commons Attribution Non-Commercial License (http://creativecommons.org/licenses/by-nc/3.0/) which permits unrestricted, non-commercial use, distribution and reproduction in any medium, provided the work is properly cited. 